\title{
BIODESIGN UMA ECOAPRENDIZAGEM: CONHECIMENTO, CONSCIÊNCIA E NOVAS RELAÇÕES COM A VIDA
}

\author{
Marilza Vanessa Rosa Suanno \\ Universidade Federal de Goiás - UFG (Brasil) \\ marilzasuanno@uol.com.br. https://orcid.org/0000-0001-5892-1484 \\ Carlos Gustavo Martins Hoelzel \\ Universidade Federal de Goiás - UFG (Brasil) \\ carlos.gustavo.ufg@gmail.com. https://orcid.org/0000-0003-3136-7270
}

\begin{abstract}
Resumo. O presente artigo objetiva apresentar uma perspectiva permacultural e transdisciplinar emergente e em desenvolvimento no Curso de Design da Faculdade de Artes Visuais da Universidade Federal de Goiás (FAV/UFG, 2018), no BioDesign Ecolab (FAV/UFG, 2018) e no Programa Formativo de Didáticas e Pedagogias Inovadoras em Design (PG002-2019i/Extensão - SIGAA). Tais projetos encontram-se interligados e visam inovar nos processos formativos e nos projetos de ensino desenvolvidos na FAV/UFG, estando esses em sintonia com as finalidades e os princípios da Universidade. Apresentam-se, na sequência, articulações entre educação e design ao referir-se a tal proposta educacional implantada em 2019, tendo por intuito compartilhar reflexões e experiências inovadoras e criativas emergentes na educação superior, fruto de um esforço coletivo e transdisciplinar de docentes da FAV/UFG com contribuições e parcerias de docentes da Faculdade de Educação (FE/UFG), Faculdade de Agronomia (FA/UFG) e Curso de Arquitetura e Urbanismo e Curso de Artes Visuais. Tais parcerias, no campo da investigação e da vivência das questões de formação universitária por diversos olhares e referenciados em ciências da terra, do planejamento e das artes, buscam produzir um outro modo de viabilizar de aprender e aplicar o conhecimento universitário.
\end{abstract}

Palavras-chave: Educação Superior, inovação, permacultura, design, transdisciplinaridade.

\section{BIODESIGN AN ECOOPRENDIZATION: KNOWLEDGE, CONSCIOUSNESS AND NEW RELATIONSHIPS WITH LIFE}

\begin{abstract}
The present article aims to present an emerging and developing permacultural and transdisciplinary perspective in the Design Course at the Faculty of Visual Arts at the Federal University of Goiás (FAV/UFG, 2018), at BioDesign Ecolab (FAV/UFG, 2018) and in the Innovative Design Didactics and Pedagogies Training Program (PG002-2019/Extension - SIGAA). Such projects are interconnected and aim to innovate in the training processes and teaching projects developed at FAV/UFG, which are in line with the purposes and principles of the University. Following is the articulation between education and design when referring to this educational proposal implemented in 2019, aiming to share reflections and innovative and creative experiences emerging in higher education, the result of a collective and transdisciplinary effort by FAV teachers/UFG with contributions and partnerships from professors from the Faculty of Education (FE/UFG), Faculty of Agronomy (FA/UFG) and Architecture a nd Urban ism Course and Visual Arts Course, partnerships in the field of research and experience of university training issues through different perspectives and referenced in earth sciences, planning and the arts, which together seek to produce another way of making it possible to learn and apply university knowledge.
\end{abstract}

Keywords: Higher Education, innovation, permaculture, design, transdisciplinarity. 


\title{
BIODISEÑO UN APRENDIZAJE ECOLÓGICO: CONOCIMIENTO, CONCIENCIA Y NUEVAS RELACIONES CON LA VIDA
}

\begin{abstract}
Resumen. El presente artículo tiene como objetivo presentar una perspectiva permacultural y transdisciplinaria emergente y en desarrollo en el Curso de Diseño de la Facultad de Artes Visuales de la Universidad Federal de Goiás (FAV/UFG, 2018), en BioDesign Ecolab (FAV/UFG, 2018) y en el Programa innovador de formación didáctica y pedagógica en diseño (PG002-2019/Extensión - SIGAA). Dichos proyectos están interconectados y tienen como objetivo innovar en los procesos de capacitación y proyectos de enseñanza desarrollados en FAV/UFG, que están en línea con los propósitos y principios de la Universidad. A continuación, se presenta la articulación entre educación y diseño al referirse a esta propuesta educativa implementada en 2019, con el objetivo de compartir reflexiones y experiencias innovadoras y creativas que surgen en la educación superior, el resultad o de un esfuerzo colectivo y transdisciplinario por parte de los docentes. de FAV/UFG con contribuciones y asociaciones de maestros de la Facultad de Educación (FE/UFG), Facultad de Agronomía (FA/UFG) y Curso de Arquitectura y Urbanismo y Curso de Artes Visuales, asociaciones en el campo de la investigación y experiencia en temas de la educación universitaria a través de diferentes perspectivas y referenciadas en ciencias de la tierra, planificación y artes, que en conjunto buscan producir otra forma de hacer posible el aprendizaje y la aplicación del conocimiento universitario.
\end{abstract}

Palabras clave: Educación, innovación, permacultura, diseño, transdisciplinariedad.

\section{Introdução}

Impulsionados por um forte desejo de construir juntos novas vias educativas, outras finalidades educativas, outros modos de desenvolver o processo formativo, um grupo de professoras e de professores da Universidade Federal de Goiás - UFG (Goiás/Brasil) se uniu para produzir coletivamente um tipo de ruptura com o ensino limitado à perspectiva disciplinar a fim de superar a fragmentação do conhecimento e, a partir disso, criar transformações no Projeto Pedagógico do Curso de Designe Autoria/FAV/UFG. Metaforicamente, podemos dizer, então, que há um coletivo de docentes e de estudantes que "se uniram para amassar o pão para ver como vai ficar o lanche, para ver como vamos nos alimentar desse projeto", desse processo, das relações humanas, das novas relações com o conhecimento e a formação, das novas relações com o pensamento que se complexifica e incorpora a cultura sustentável, a qual sistematiza formas de hábitos e de costumes com base na economicidade e na progressão dos sistemas naturais e permaculturalii, que, além de preservar e de ampliar a energia dos sistemas, propõe uma ecologia mental aderida à natureza local. Dessa forma, o impacto na projetação dos produtos do Design e o próprio processo de criação se moldam na capacidade de sensibilidade do autor que se mimetiza com as questões e não apenas as analisa por métricas. Tal impacto tem sido acompanhado em diversas iniciativas de universidades brasileiras, principalmente, na adoção dessas ideias eco e sociocentradas, em iniciativas como as da Universidade Federal de Santa Catarina e de seu grupo multidisciplinar de estudo em permacultura. Porém, nos cursos de Design, especificamente, o viés ecocentrado tangencia-se, normalmente, pelo estudo da biônica e da biomimética aplicadas em estética e em funções de produto. No Caso do Curso de Design e Autoria da UFG, dois aspectos se diferenciam desse universo de mais de 450 cursos de graduação e técnicos do país: o primeiro é o aspecto da autoria, pois o aluno passa a ser autor do seu próprio conhecimento viabilizado sempre pela experiência de vivenciar o espírito do tempo em que está projetando e percebendo a ação do resultado do seu projeto na cultura material de uma comunidade durante todo o ciclo de vida de um produto. O segundo aspecto, evidencia a ideia de permanência peculiar da permacultura, 
coloca-se transversalmente no currículo como uma linha a qual articula o pensamento do humano, meio (paisagem, animal, vegetal e recursos), energia e sistemas que mudam a ação de projetar. Trata-se de uma proposta de Design para ciclos de vida nos quais se produzem e se alimentam os métodos projetuais com conhecimentos vivos, referencias da natureza e compreensão da complexidade social humana.

\section{Metodologia}

A metodologia desenvolvida foi do tipo pesquisa-ação-formação de abordagem qualitativa e contou com quatro etapas: a) construção coletiva e implantação do Projeto Pedagógico do Curso de Design da Faculdade de Artes Visuais da Universidade Federal de Goiás (FAV/UFG, 2018); b) construção coletiva e transdisciplinariii do projeto de BioDesign Ecolab (FAV/UFG, 2018) com parcerias entre docentes da Faculdade de Educação (FE/UFG), Faculdade de Agronomia (FA/UFG) e Curso de Arquitetura e Urbanismo e Curso de Artes Visuais; c) criação, desenvolvimento e avaliação do Programa Formativo de Didáticas e Pedagogias Inovadoras em Design (PG0022019iv/Extensão - SIGAA), que contou com a participação de docentes da Faculdade de Artes Visuais; d) revisão de literatura e de reflexões coletivas sobre educação, formação humana e profissional, permacultura e biodesign.

\section{Desenvolvimento}

Almejamos, na universidade pública, a construção de projetos formativos e de projetos de ensino que mobilizem razão, emoção, compromisso socioambiental e formação profissional a fim de contribuir para a construção de mundo melhor a todos e a todas. Para tal, nutrimo-nos do diálogo democrático, da pluralidade de ideias, do conhecimento científico e, neste projeto, em especial, almejamos nos guiar por uma consciência integral capaz de produzir ações transformadoras nas relações indivíduo/natureza/sociedade (D’Ambrósio, 1999).

A perspectiva transdisciplinar e permacultural em desenvolvimento no Curso Design (FAV/UFG, 2018), no BioDesign Ecolab e no Programa Formativo de Didáticas e Pedagogias Inovadoras em Design (PG002-2019/ Extensão - SIGAA) demonstram sintonia com finalidades da universidade, uma vez que a UFG é uma "instituição comprometida com a justiça social, os valores democráticos e o desenvolvimento sustentável, tem por finalidade transmitir, sistematizar e produzir conhecimentos, ampliando e aprofundando a formação humana, profissional, crítica e reflexiva" (Art. $5^{\circ}$ do Estatuto da UFG).

Em consonância com as finalidades e os princípios estatutários da UFG, emergem, no Curso de Design (FAV, 2018), projetos, processos e ações socialmente comprometidos com: a) defesa da democracia, estímulo à cultura, à arte e ao desenvolvimento científico, tecnológico, socioeconômico e político do País; b) defesa da democratização da educação; c) defesa da qualidade de ensino com orientação humanística e preparação para o exercício pleno da cidadania; d) respeito à liberdade, à diversidade e ao pluralismo de ideias sem discriminação de qualquer natureza; e) universalidade do conhecimento e fomento à interdisciplinaridade; f) indissociabilidade entre ensino, pesquisa e extensão; g) gratuidade do Ensino, cuja manutenção é responsabilidade da União; h) defesa da paz, dos direitos humanos e do meio ambiente; i) defesa da laicidade e j) defesa do diálogo e da cooperação (Art. 4, Estatuto UFG).

O coletivo de docentes envolvidos nos referidos projetos inspira-se em múltiplas perspectivas teóricas, valoriza a sustentabilidade e a articula a cultura da permanência e 
a ampliação da consciência planetária. De tal modo, propõe uma formação universitária sólida, que valorize ciência com consciência (Morin, 2008) e que crie processo de ensinoaprendizagem por meio de vivências, de experiências e de imersões coletivas e comunitárias. Para Morin (2008), ciência com consciência é um conceito que entrelaça dois sentidos consciência moral e consciência autorreflexiva, pois "mais do que nunca, se impõe a necessidade do autoconhecimento do conhecimento científico, que deve fazer parte de toda política da ciência, como da disciplina mental do cientista" (Morin, 2008, p. 21).

Essa perspectiva tem o objetivo de produzir ruptura paradigmática, reformar o pensamento, criar outros modos de ensinar e de aprender, inquietar os participantes do processo formativo para produzir novas relações com a vida, com o conhecimento, com as técnicas, com o conhecimento tácito e declarativo de uma outra consciência, com a sociedade e com a natureza. Para quem sabe, assim, serem capazes de imaginar e de criar eco ações as quais dependem de reflexão não apenas sobre conhecimento, mas também supram o aspecto atitudinal. A proposta curricular do Design e Autoria e atitude está no mesmo nível das habilidades e dos conhecimentos no projeto pedagógico. Uma ecoação pratica-se numa perspectiva de agir sensível e intuitivamente na sua atmosfera de vida, ampliando o pensamento para o passado (história) e para o futuro, sentindo a tendência e seus caminhos naturais, independentemente de conceitos produtivistas e de facilidades da vida humana que conflituam com outros sistemas de vida em desequilíbrio destrutivo.

$\mathrm{Na}$ perspectiva de um biodesign, a atividade de projetar é um imaginário de cenários futuros interconectados. Biodesign ou design da vida é um caminho do meio por onde as ruas curvas sempre estão em constante dinâmica e exigem uma metodologia de projetação plástica de alta adaptabilidade, como a própria natureza. Considerando o campo metodológico do design, possivelmente aí é que haja a maior contribuição do biodesign junto as eco ações. Trata-se da necessidade de integrar as variáveis sociais de diversos seres vivos aos conhecimentos antropológicos e seus lugares de estar, seus cenários.

Dessa forma, a fim de guiarmo-nos por um modo de pensar complexo, transdisciplinar e permacultural, faz-se imprescindível, na formação universitária, religar conhecimentos científicos, saberes ancestrais, saberes de povos originários, arte, estética, imaginário, criando condições para emergir um modo de "sentipensar" e agir complexo, por meio de relações dinâmicas, sistêmicas, recursivas e retroativas em ciclos emergentes e insurgentes.

Nesse processo formativo parece fundamental buscar promover a ampliação da consciência humana e da compreensão da condição humana e planetária que têm um destino em comum, colocando-nos frente ao desafio de criar atividades, vivências e dinâmicas educacionais que façam sentido para os atores desse processo. Para tanto, a reflexão em torno de temas e de práticas por permacultura, ciclos de vida e biodesign alcançam aprofundamentos que vão da qualidade de imersão até a análise com maior acurácia quanto ao resultado do uso dos conhecimentos, métodos e ferramentas ao se falar de aprendizagem significativa individual, social e ecológica.

Na abordagem da Permacultura, Bill Mollison e Reny Mia Slay (1998), num posicionamento crítico aos modelos de produção altamente entrópicos, publicaram Introduction to Permaculture, definindo a permacultura como "um sistema de design para criação de meio ambientes humanos sustentáveis". Trata-se de uma perspectiva de permanência auspiciosa num lugar. 
A ética da ecorresponsabilidade norteia os sujeitos e as suas relações num sistema permacultural, inspirando-se em formas de agricultura integradas e em sistemas naturais, ou seja, uma perspectiva sistêmica de equilíbrio ecoenergético em recortes de células espaciais bem definidas. Porém não se limita a isso, uma vez que o aprender dentro da cultura da permanência é necessariamente vivencial e experiencial. Assim, a mimetização com o meio ambiente, a anaminese dos problemas, a indissociabilidade entre a gestalt do humano e da terra são elementos chave para impulsionar o processo de mudança de consciência e de reforma nos processos educacionais.

Outro ponto importante da teia de pensamento para uma educação em biodesign mais densa e significativa está no fato de que as áreas de projetos de produtos, processos ou serviços passam a majorar a importância das tendências e buscam vislumbrar o Zeitgeit (o espírito do tempo) que revela as tendências dos sistemas. Esse apontamento nos impõe questionamentos quanto ao estado presente das coisas e das suas obsolescências. Igualmente, impulsiona processos que visam a projetar não apenas o produto, mas seu ciclo de vida, o que pode redimensionar as buscas e as intencionalidades, bem como favorecer para que a energia humana e a energia dos sistemas compartilhados tendam ao equilíbrio.

De acordo com Hoelzel (2019), Victor Joseph Papanek (2002), de literatura conhecida no Brasil, desde antes dos anos 1990, apontava para uma ideia de design e de arquitetura social ecologicamente responsável como necessária ao equilíbrio entre reais necessidades e uso de recursos naturais e da energia humana gasta na produção. Discordava da perspectiva antiga na qual as máquinas com alta capacidade de replicar objetos e de baratear custos imediatos formavam a ideia dominante. Ele, justamente, estava questionando que "o barato sai caro" e que replicar objeto, embora mais barato, diminui a capacidade de adaptação dos desenhos dos produtos aos seus consumidores, os quais perdiam a identidade com seu meio e com ferramentas estereotipadas. Ocorre, assim, a perda de identidade e, por consequência, surge a irresponsabilidade com os objetos dos cenários cotidianos.

Nessa linha de pensamento, postula-se o biodesign, o qual constitui-se em uma perspectiva ética da cultura da permanência, uma perspectiva metodológica projetual e educacional da biomímese e uma perspectiva reflexiva, abraçando os fenômenos como experiências únicas com diversos atores, mediadores e cenários. Tal perspectiva fica mais clara quando se entende a ética da permacultural como focada nos princípios que motivam ou orientam o comportamento humano não apenas na relação com o meio natural, mas igualmente às normas e aos valores seguidos na permanência em sítio (espaço de ocupação, interação, troca e síntese de energias para qualidade de vida do ator e do cenário). É a ideia do "berço ao berço"” de Braungard e McDnough (2002) colocando para os designers a responsabilidade de projetar não só a forma dos produtos, mas o ciclo de vida deles conosco.

No processo formativo, a mímese emerge como estratégia para alavancar o processo de investigação, internalização nos meios naturais para identificar sua sistêmica e aplicá-la na forma de processo, método de projeto biônica em design dos artefatos e dos sistemas de cada dia.

Quanto à perspectiva reflexiva do biodesign, os sentidos imanentes das experiências e dos repertórios de aprendizados sobre os atores e os cenários encontram seu melhor registro nas poéticas. Isso porque, nelas, amalgamam-se significados e sentidos de forma criativa, ou seja, o ato de aprender é dinâmico, ou melhor, o que se aprende muda constantemente na nossa mente, e a produção de sentidos (com o 
"sentipensar") é mais evidente nas experiências viscerais, as quais, de fato, mudam nossa consciência, construindo nossas identidades por meio da reflexão, das artes, das poéticas. Sentipensar é uma estratégia didática favorável ao resgate da dimensão emocional a fim de sensibilizar o sujeito em torno do conhecimento, da autoaprendizagem e da ecoaprendizagem.

Moraes e Torre (2004, p. 63) definem sentipensar como sendo "processo mediante o qual se colocam para trabalhar conjuntamente o sentimento e o pensamento, a emoção e a razão, evidenciando, assim, o quanto nossas estruturas cognitivas são irrigadas pelos nossos componentes emocionais, pelos nossos sentimentos e crenças". Moraes (2008, p. 164) analisa que sentipensar pode contribuir para a construção de práticas pedagógicas que contribuam para "formar indivíduos não apenas profissionalmente competentes, mas, sobretudo, cidadãos eticamente bem formados, pessoas sadias, emocionalmente equilibradas e felizes".

Um exemplo atual desses pensamentos encontra-se, hoje, na UFG, no curso de graduação em Design, que busca, no fazer e no refletir, a construção de ambientes de aprendizagem mais íntegros. Um novo currículo foi elaborado calçado numa linha de projetos com criação individual e coletiva, que valoriza processos imersivos e autorais. Em parte, busca-se atender a um público que espera os designers de formação acadêmica serem inteligentes, éticos e estratégicos o suficiente para não criarem mais destruição.

Observamos que a sustentabilidade e o design ecocentrado não se resolvem somente por pesquisa e produção de conhecimento isolados, isto é, passam pela ampliação da consciência e pela assumência de novas atitudes e de relações com o ato de criar e a responsabilidade socioambiental com o produto criado. Nesse sentido, o ambiente de formação acadêmica tem sido insuficiente, haja vista poucos professores de projeto terem a experiência de desenvolver um produto ou um sistema com efetivos requisitos ecológicos e terem testado suas funções.

No meio universitário, ainda, falta a construção de uma maior aproximação entre teoria e prática, além da ausência do exercício coletivo de, ao se relacionar teoria e prática, criar ações/projetos/produtos transformadores, ou seja, viabilizar práxis inventivas (Lucarelli, 2009).

Questionamos os limites de uma formação acadêmica que produz especialistas, ou seja: se por um lado tornar-se um especialista é importante para se ter acurácia e perfeição em detalhe, por outro pode tornar o profissional insipiente em várias coisas que cercam a vida, o trabalho e as interfaces emergente de sua área de conhecimento.

Buscando superar os limites da formação, da lógica dominante e do enfoque educacional restritivo (ora excessivamente pragmático, ora excessivamente teórico) é que o Laboratório BioDesign Ecolab surge com o intuito de produzir experiências, substancialmente, significativas entre acadêmicos/as e docentes do curso de Design, assim lhes oportunizando vivenciar e construir novas formas de aprender e de ensinar, mobilizados por conceitos e por práticas da permacultura, da sustentabilidade e da ecoeficiência, além de desenvolver produtos, sistemas e bioconstrução para um futuro imediato, dentre de uma ética permacultural e transdisciplinar.

Para ajudar a entender a proposta do BioDesign Ecolab, indicamos, para os participantes do projeto, a leitura de Braungard e McDnough (2014), que esclarece a sustentabilidade na ideia de design. Os autores englobam boa parte dos postulados de Mollison e Slay (1989) e Papanek (2002) da permacultura. Sintetizam, igualmente, suas ideias na expressão conceito "do berço ao berço", colocando, aos designers, a 
responsabilidade de projetar não só a forma dos produtos, mas um ciclo de vida, pensando, por exemplo, nos materiais e se perguntando e gerenciando: de onde vieram? Como e em quanto tempo voltarão à origem?

Tais autores, também, trazem o conceito de ecoeficiência que nos mobiliza a refletir sobre como "fazer mais com menos", popularizando a ideia de reduzir, reusar, reciclar e regulamentar. Aqui, vemos um alinhamento com Mollison e Slay, pois a lógica da ecoeficiência pode ser melhor pesquisada e, estrategicamente, relacionada ao uso mínimo da energia para ativar qualquer sistema, ou seja: não usar se não necessário e todo o excedente ser distribuído para outros sistemas.

Assim, no Ecolab (Hoelzel, 2019), alunos voluntários (muitos calouros) e participantes de pesquisas do curso de design foram convidados não somente a conhecer técnicas de biodesign e de permacultura, mas também aplicá-las, buscando um sentimento de apropriação e de cuidado com seu espaço. Uma das primeiras consequências foi se questionarem a respeito do próprio sistema de vida doméstica, o que apareceu muito em expressões como: "quanta embalagem eu uso!", "quanto lixo poderia virar fertilizante" e "quero ajudar a plantar árvore!".

Outro fato marcante foi os alunos, por conta própria, começarem a ver a universidade como um sistema dispendioso. Muito papel descartado indo para o lugar errado, muitos móveis podendo ser reconfigurados, muita oportunidade para redesenho de função de produtos diversos. Com essas percepções e a necessidade, inclusive, de os professores terem uma real experiência, as temáticas de projeto do curso foram tomando a sustentabilidade como premissa e tema para o design de produtos e de sistemas inovadores. Isso significa que Ecolab e o currículo do curso de design caminham juntos na busca do designer integral.

Mollison e Slay (1998), Papanek (2002), Braungard e McDnough (2002), Hoelzel (2019), Boff (2012), Lazlo (2002), Morin (2008), Nicolescu (1999), Suanno (2015), dentre outros, apresentam reflexões e perspectivas significativas e provocadoras para reorganização da formação universitária e para ampliação da formação em Biodesign. $O$ estudo e a compreensão de tais perspectivas têm potencial para possibilitar diálogos, problematizações, conhecimentos e a criação de iniciativas insurgentes que impulsionassem uma macrotransição no pensamento e na ação humana, favorecendo processos de tomada de consciência com profundas mudanças nos princípios, valores, modos de pensar/sentir/agir/produzir/consumir/viver, construindo, dessa maneira, novas relações sociais e culturais com a vida e com o meio ambiente. Isso, poeticamente, levarnos-ia a retomar as interações perdidas, os elos perdidos.

Educar para produzir uma macrotransição demandaria, conforme Laszlo (2002), a superação de velhas ideias e a promoção de mudanças na vida coletiva e no modo como pensamos, sentimos, agimos e nos comprometemos com o planeta Terra. Assim, o referido autor propõe a superação das ideias de que: a) a natureza é inesgotável; b) a natureza é uma máquina gigante; c) a vida é uma luta; d) a riqueza se distribui por toda sociedade; e) quanto mais você consome, melhor você é; f) o futuro não é problema nosso. Enfim, o autor propõe a superação da cosmovisão do domínio e da conquista da natureza pela cosmovisão do respeito, do cuidado e da proteção da natureza, o que inclui os seres humanos como partes da natureza e da cultura.

Nessa mesma perspectiva, Boff, Torro e Schindler (2012)v argumentam que os seres humanos estão em perigo de extinção, e não o planeta Terra, uma vez que, caso os humanos desapareçam da face da Terra, o planeta se adaptará e se manterá sem a presença 
dos mesmos. De tal modo, há de se problematizar e de se construírem proposições capazes de impulsionar a superação da lógica de mercado, do consumismo, da indiferença, irresponsabilidade e inconsequência desenvolvimentista cunhada na lógica da dominação, exploração, acumulação, consumo e poder econômico. Mudar o atual caminho do capitalismo é cada vez mais improvável, porém não é impossível (Suanno, 2016).

No meio universitário, a reflexão sobre uma potencial macrotransição demandaria ruptura paradigmática (Moraes, 2008; Santos, 2000), esforço por pensar complexovi (MORIN, 2007), consciente e comprometimento (Hessel, 2011) a fim de impulsionar ensino, pesquisa e extensão no sentido de construir transformações nas percepções humanas e articulação entre os conhecimentos com o intuito de desvelar a realidade em dimensões locais, nacionais e globais.

No presente artigo, propusemo-nos a apresentar os projetos como perspectivas que visam à construção de transformações educativas nutridas pela curiosidade e pelo conhecimento viabilizadas por meio de vivências e de imersões dialógicas, comunitárias, cooperativas, solidárias, pacíficas e capazes de construir gestão democrática dos conflitos. Nesse sentido, sustentamos: a) integração das quatrovii ecologias (BOFF, 2012); b) ensino transdisciplinar (Suanno, 2015) impregnado da cultura da permanência (Hoelzel, 2019), guiado pela aventura, pelo conhecimento e pela ciência com consciência (Morin, 2008) em prol de uma formação para a ampliação do conhecimento científico e do compromisso social, ambiental e cultural e na produção de uma sociedade mais saudável, sustentável, democrática, fraterna e justa.

Processos de inovação educativa como os apresentados, neste artigo, são processos incertos, são apostas que demandam dos sujeitos: conhecimentos, sensibilidades, compromissos e intencionalidades para a construção de práxis do tipo inventiva (Lucarelli, 2009) e inovações didáticas complexas e transdisciplinares (Suanno, 2015); demanda da instituição: condições de trabalho, estímulo à inovação didática, valorização do trabalho docente na graduação e na articulação entre pesquisa/ensino/extensão/gestão universitária, uma vez que

Inovações didáticas complexas e transdisciplinares no trabalho docente se organizam a partir da reforma do pensamento e da emergência de novas finalidades educacionais, o que remete a rupturas com o ensino tradicional, disciplinar e centrado na exposição docente. As práxis inovadoras guiadas pela sensibilidade humana, pela ciência com consciência, pela valorização do humano, da criatividade, do diálogo, dos princípios da transdisciplinaridade e operadores do pensamento complexo na busca por articular razão-emoção-corporeidade no processo educativo, por visar e ampliação da percepção, da consciência e da aprendizagem dos envolvidos no processo didático (SUANNO, 2015).

De tal modo, inovar na educação superior demanda colocá-la a serviço de novas finalidades (Saviani, 1985). A partir disso, o curso de Design da UFG, o BioDesign Ecolab e Programa Formativo (PG002-2019) assumem finalidades formativas orientadas pela permacultura e com viés complexo e transdisciplinar. Há que se considerar que um dos principais gargalos é a própria formação do professor que, pouco ou nada, foi orientado à inovação. Basta considerar que a formação por conhecimento declarativo e os conteúdos abstraídos das experiências de outros, normalmente, são as bases dos designs, arquitetos e pedagogos (sendo estes designers do conhecimento). Dessa forma, pouco se aprende a aprender, e esse trauma é repassado de geração em geração nas universidades. 
Duas lógicas são importantes abordar aqui: a primeira é a angústia do docente de ensinar a fórmula primeiro e não o mergulho no problema, o que, consequentemente, deixa o aluno longe dos princípios de conhecimentos que podem gerar "n" fórmulas. Assim, começa-se a matar o futuro pesquisador. A segunda lógica é a da crença na fórmula, ensina-se a aprender a "verdade científica" da fórmula, mas não se ensina a desaprendê-la para poder gerar novos princípios de perceber o mundo e, por consequência, atingir inovações. Assim, há de se considerarem e de se integrarem, no processo formativo, as cinco perspectivas globais nos estudos da criatividade (Mitjáns Martínez, 1997), que compreendem a criatividade como: a) processo, b) produto, c) condições, d) pessoas e e) integração.

No intuito de contribuir nesse processo e de viabilizar formação docente com vivências, imersões e compartilhamento de saberes, finalidades e estratégias, criamos o 'Programa Formativo de Didáticas e Pedagogias Inovadoras em Design' (PG002-2019) que visa a: a) impulsionar o processo de implantação do novo currículo do Curso de Design (FAV/UFG); b) criar coletivamente projetos de ensino que sejam capazes de formar profissionais de nível superior com conhecimentos, habilidades, competências e atitudes para desenvolver projetos de Design, podendo atuar como planejadores, executores e gestores do projeto e de processos, atentos ao caráter estético, cultural, ecológico, étnico-cultural, com consciência individual, social e pública, exercendo suas atividades na sociedade com responsabilidade civil e ética; c) impulsionar o processo de implantação do novo PPC do Curso de Design de Ambientes (FAV/UFG) por meio da formação do quadro docente e da construção coletiva e colaborativa dos projetos de ensino; d) fazer do curso uma experiência de profissionalização abrangente, motivadora e transformadora para os atores envolvidos; e) buscar, nas intersecções dos domínios dos campos da Educação e do Design, uma perspectiva orientada a inovação radical nos processos de aprendizagem e ensino; e f) possibilitar o diálogo docente com perspectivas pedagógicas emergentes e sustentáveis.

O Programa Formativo Didático Pedagógica em Design pretende promover reflexões sobre os princípios norteadores para a formação do profissional do novo PPC do Curso de Design. As experiências de turma de projeto, na nova proposta curricular, com no máximo 15 alunos em laboratório, já ensinou que o estudo dos conteúdos tradicionais vem depois do estudo dos problemas e, muitas vezes, junto. As propostas projetuais mais bem sucedidas têm um componente de teste interessante, ou melhor, os produtos e os cenários de diferentes épocas são simulados e, portanto, a compreensão do contexto sócio-histórico-cultural é base de projeto.

Para os docentes, em meio ao aprendizado em laboratório, a riqueza das questões trazidas pelos alunos tem gerado projeto de pesquisa que se prolonga em diversas disciplinas, desconfigurando-se a orientação de apenas um docente numa coletânea de abordagens, impulsionando a inovação. Tais assuntos são combustíveis constantes à formação do professor que toma uma dinâmica ininterrupta de reflexão e de inovação do processo pedagógico de campo (laboratório e cenários de ação) e de produção intelectual. Assim, permitiram-se construir, coletivamente, estratégiasviii que possibilitem implantar tal projeto formativo alinhado aos princípiosix norteadores do Curso. 


\section{Considerações finais}

Almejamos, com os projetos apresentados nesse artigo, contribuir para criar, no Curso de Design, o que Almeida e Pimenta (2014) denominaram como sendo uma nova cultura acadêmica nos cursos de graduação: a) o direito do estudante de desenvolver uma postura frente ao saber que supere a especialização estreita; b) a problematização das informações e a garantia da sua formação como cidadão e como profissional cientista compromissado com a aplicação do conhecimento em prol da melhoria da qualidade de vida de toda a sociedade; c) a possibilidade do desenvolvimento do pensamento autônomo, substituindo a simples transmissão do conhecimento pelo engajamento dos estudantes num processo que lhes permita interrogar o conhecimento elaborado, pensar e pensar criticamente; d) o ensejo da resolução de problemas, o estímulo da discussão, o desenvolvimento de metodologias de busca e de construção de conhecimentos (ensinar com pesquisa); e) o confronto dos conhecimentos elaborados e as pesquisas com a realidade; f) a mobilização das visões interdisciplinares e transdisciplinares sobre os fenômenos; g) o apontamento das soluções aos problemas sociais (ensinar com extensão) e h) a criação de uma nova cultura acadêmica que valorize o trabalho dos docentes na graduação.

Guiados por princípios da permacultura, sustentabilidade e transdisciplinaridade, intencionamos a construção coletiva de um pensamento mais complexo, inovador e, ao mesmo tempo, com uma força de síntese sensível no âmbito da formação acadêmica e tácita do designer.

\section{Referências}

D’Ambrósio, U. (1999). Educação para uma sociedade em transição. Campinas: Papirus. Hoelzel, C. G. (2019). Formando para o Biodesign. Revista Estimuladamente, 40-41. Recuperado de https://revistaestimuladamente.com.br/2019/03/14/formando-parao-biodesign/.

Lucarelli, E. (2009). Teoría y práctica en la universidad: la innovación en las aulas. Buenos Aires: Miño y Dávila Editora.

Mcdonough, W. e Braungart, M (2002). Cradle to cradle:rRemaking the way we make things. New York: North Point Press.

Mello, A. F., Almeida Filho, N. e Ribeiro, R. J. Por uma universidade socialmente relevante. http://portal.mec.gov.br/dmdocuments/cne_alexfiuza.pdf.

Mollinson, B. e Slay, R. M. (1998). Introdução à permacultura. Brasília MA/SDR/PNFC.

Moraes, M. C. e Torre, S. (2004). Sentipensar: fundamentos e estratégias para reencantar a educação. Petrópolis: Vozes.

Morin, E. (2008). Ciência com consciência. Rio de Janeiro: Bertrand Brasil.

Suanno, M. V. R. (2015). Didática e trabalho docente sob a ótica do pensamento complexo e da transdisciplinaridade [Tese de doutorado, Universidade Católica de Brasília]. Brasília: UCB. 
Suanno, M. V. R. (2016). Mudar o atual caminho do capitalismo é cada vez mais improvável, porém não é impossível. In J. C. Libâneo, M. V. R. Suanno e S. V. L. Rosa. (Org.). Didática e currículo: impactos dos organismos internacionais na escola e no trabalho docente (pp. 95-130). Goiânia: Espaço Acadêmico/Ceped Publicações.

Suanno, M. V. R. (2015). Educar em prol da macrotransição: emerge uma didática complexa e transdisciplinar. In M. A. B. e Romilda T. Ens (Org.). Complexidade e transdisciplinaridade: novas perspectivas teóricas e práticas para a formação de professores (pp. 199-213). Curitiba: Aprris.

Papanek, V. J. (2002). Arquitetura e Design: ecologia e ética. São Paulo: Almedina.

\footnotetext{
' Carlos Gustavo Martins Hoelzel (coordenador), docentes da UFG que nesse programa são instrutorsupervisor: Rosane Costa Badan, Marilza Vanessa Rosa Suanno, Samuel Jose Gilbert de Jesus, Carolina Ferreira da Fonseca, Dorivalda Santos Medeiros Neira, Regis de Castro Ferreira, Gustavo Soares de Castilho (servidor), Dieniffer Pereira Nunes dos Santos Costa (monitora), Jordana de Paula Costa (monitora), Beatriz Maria Parreiras Pereira (monitora), Marcelo Langer (membro externo), João Henrique Suanno (membro externo).

ii Permacultura, ou cultura da permanência, desenvolveu-se na década de 70 por Bill Mollison e David Holmgren na Tasmânia. Tratava-se de uma resposta às questões que envolviam o sistema industrial e agrícola da época. Sua base é a ecologia para sistemas humanos sustentáveis, valorizando conhecimento tradicional, agricultura ancestral, construções eficientes, equilíbrio (mental, físico e espiritual), diversidade, recursos naturais e sustentabilidade, pensando no equilíbrio energético, cuidando da terra, das pessoas e dos outros seres.

iii Transdisciplinaridade, conforme Suanno (2015), transcende a disciplinaridade e se caracteriza por ser uma pulsão religadora entre conhecimentos, saberes, práticas, culturas, competências e experiências, que visam ampliar a compreensão sobre o ser humano e sobre o mundo presente. Sendo assim, caracteriza-se àquilo que está ao mesmo tempo entre as disciplinas, através das diferentes disciplinas, e vai mais além de qualquer disciplina (NICOLESCU, 1999). De tal modo, a transdisciplinaridade assume o desafio de pensar complexo e ecologizar saberes, considerando aspectos multirreferenciais e multidimensionais do objeto/fenômeno em estudo. Para tal, articula razão, emoção e atitude transformadora ao trabalhar com uma razão sensível no intuito de produzir práxis complexa e transdisciplinar.

iv Na UFG, os projetos de extensão são cadastrados no Sistema Integrado de Gestão de Atividades Acadêmicas - SIGAA e o projeto de extensão intitulado 'Programa Formativo de Didáticas e Pedagogias Inovadoras em Design' tem por código PG002-2019 e visa a impulsionar o processo de implantação do novo currículo do Curso de Design de Ambientes (FAV/UFG) e aprimoramento dos atores dos demais cursos de design da FAV e discentes interessados em monitoria por meio da formação do quadro docente e do diálogo com perspectivas pedagógicas emergentes e sustentáveis. Predispõe-se ao desafio de construir oportunidades formativas para os docentes dos Cursos de Design pensarem complexo e construírem, coletivamente, projetos de ensino que viabilizem a religação de conhecimentos, saberes, culturas e práticas a fim de alcançar os objetivos formativos do PPC do Curso. Por outro lado, faz-se necessária a sistematização da experiência didático pedagógica alcançada até o momento nos cursos de design da unidade para identificar as convergências que unem a epistemologia da área no local. Ainda, o programa é parte da ação do núcleo docente estruturante que colocará seus esforços nas melhores práticas coletivas para, de fato, causar a reformulação curricular efetiva. É um programa aberto a todas as áreas de design, contando com aproximadamente vinte participantes, os quais desenvolvem seminários e palestras temáticas
} 
desde fevereiro de 2019. O Programa Formativo foi criado pelo coletivo de professores e se desenvolveu por meio de palestras, rodas de conversa, oficinas, dentre outros.

v Painel 'Empatia e cuidado: o paradigma e a atitude para uma nova civilização', mediado pela jornalista Renata Ceribelli, durante o Fórum de Empreendedorismo Social na Nova Economia, evento paralelo à Rio+20.

vi O pensamento complexo guia-se por princípios operadores de disjunção, conjunção e implicação, sendo esses articulados e dinâmicos: a) princípio sistêmico-organizacional, b) princípio hologramático, c) princípio retroativo, d) princípio recursivo, e) princípio dialógico, f) princípio auto-eco-organizador ou autoprodução e g) princípio da reintrodução do sujeito cognoscente no processo de construção do conhecimento, h) princípio ecológico da ação, i) princípio da enação e j) princípio ético (MORAES; VALENTE, 2008). O pensar complexo caracteriza-se por ser multidimensional, autorreferencial, multirreferenciais e ecológico.

vii Ecologia ambiental, ecologia social e política, ecologia mental e ecologia integral.

viii As estratégias utilizadas se guiaram pela problematização, pela pergunta, pelo questionamento sobre quais rupturas e quais inovações o coletivo visava a construir. De tal modo, as estratégias foram dialógicas e experimentais, desenvolvidas por meio de vivências, oficinas e diálogos em reuniões, palestras e rodas de conversa.

ix Princípios norteadores do curso de Design (FAV/UFG, 2018): a) A prática profissional - com ênfase na pesquisa e no desenvolvimento de produtos e nos processos socioculturalmente referenciados, o Design da UFG pretende contribuir para a formação de profissionais aptos às atribuições correlatas, o que o diferencia dos cursos tecnológicos e técnicos disponíveis em outras instituições. b) A formação técnica - em todo seu histórico, o curso possui uma abordagem técnica quanto aos processos de criação, de representação e de apresentação dos projetos seja ela bi ou tridimensional. A ferramenta de representação de processos criativos é reforçada para atender a uma linguagem universal, na qual se viabiliza o entendimento dos projetos em diversos âmbitos. c) A articulação entre teorias e práticas - pretende-se afastar a percepção dicotômica entre teoria e prática, gestor e executor por meio de estratégias didática ativas e da modificação dos cenários de aprendizagem. A proposta curricular aqui exposta propõe-se a colocar, sempre que possível, o discente na posição de protagonista do seu processo de crescimento intelectual e vivencial, objetivando torná-lo sujeito ativo no aprendizado, no curso e na universidade, incentivando-o a atuar como autor também responsável pelo caminho de formação numa só prática e teoria. d) A interdisciplinaridade - o papel do designer é servir de intermediador entre o ser humano, sua cultura e sua tecnologia. Por essa razão, o ensino do Design estaria pautado em uma gama de conhecimentos multidisciplinares que induz uma estrutura curricular baseada na interdisciplinaridade. Considerando que os problemas do mundo real não se apresentam ao designer conforme padrões pré-definidos, o compartilhamento de ideias e de teorias vindas de variadas disciplinas optativas de projeto disponíveis em todos semestres pode articular o curso em constantes e em renovadas dinâmicas em direção a conhecimentos diversificados e a visões múltiplas, considerando diferentes ângulos de uma mesma questão. Além disso, em vista das interfaces do design de produto e dos processos com a arquitetura e com as artes, o curso busca reforçar os laços de coprodução e disponibilizar classes entre os núcleos disciplinares correlatos, ressaltando a realidade profissional de equipes multidisciplinares. Os convênios com universidades estrangeiras são uma realidade na UFG; esses mecanismos de intensificar o intercâmbio internacional, cooperações técnicas, culturais e científicas proporcionam aos alunos e aos professores o contato com outras culturas, complementando sua experiência curricular de forma enriquecedora. e) A formação ética e a função social do profissional - a proposta pedagógica para o curso de graduação em Design deverá assegurar a formação de profissionais capazes de compreenderem e de traduzirem as necessidades de sistemas, individuais, grupos sociais e comunidades, com relação à concepção, organização, construção e redesign dos artefatos de uso direto e indireto. O curso deverá estabelecer ações pedagógicas visando ao desenvolvimento de condutas e de atitudes com responsabilidade técnica, social e ética. Terá por princípios: a qualidade de vida dos atores sociais e a qualidade dos artefatos e dos ambientes construídos; o uso de tecnologias em respeito às necessidades sociais, culturais, estéticas e econômicas das comunidades; o equilíbrio ecológico e o desenvolvimento sustentável do ambiente natural e construído; a valorização, a preservação e a promoção das técnicas nativas principalmente em etnias mais ancestrais; a valorização e a preservação do patrimônio material e imaterial local e nacional. As diretrizes curriculares gerais têm por objetivo qualificar o estudante para o exercício profissional, proporcionando ao futuro Designer o domínio essencial das matérias necessárias à sua atuação, garantindo a habilitação única e fortalecendo seu conhecimento especializado, sem perder a noção de conjunto dos problemas e suas relações com a sociedade. 
Data de recepção: 06/06/2020

Data de revisão: $13 / 07 / 2020$

Data do aceite: $15 / 07 / 2020$ 